\title{
Pregnancy in Cystic Fibrosis: Review of the Literature and Expert Recommendations
}

\author{
Raksha Jain ${ }^{1}$, Traci Kazmerski ${ }^{2}$, Lisa Zuckerwise ${ }^{3}$, Natalie West ${ }^{4}$, Kristina Montemayor ${ }^{4}$, \\ Moira Aitken $^{5}$, Edith Cheng ${ }^{5}$, Andrea Roe ${ }^{6}$, Alexandra Wilson ${ }^{7}$, Caitlin Mann ${ }^{3}$, Sigrid \\ Ladores $^{8}$, Jacqui Sjoberg ${ }^{9}$, and Jennifer Taylor-Cousar ${ }^{10}$ \\ ${ }^{1}$ The University of Texas Southwestern Medical Center \\ ${ }^{2}$ University of Pittsburgh School of Medicine \\ ${ }^{3}$ Vanderbilt University Medical Center \\ ${ }^{4}$ Johns Hopkins University \\ ${ }^{5}$ University of Washington School of Medicine \\ ${ }^{6}$ University of Pennsylvania \\ ${ }^{7}$ National Jewish Health \\ ${ }^{8}$ University of Alabama at Birmingham School of Social and Behavioral Sciences \\ ${ }^{9}$ Affiliation not available \\ ${ }^{10}$ National Jewish Health Department of Medicine
}

November 26, 2020

\begin{abstract}
Cystic fibrosis (CF) was historically a disease largely afflicting children. Due to therapeutic advancement, there are now more adults with $\mathrm{CF}$ than children. In the past decade, medications became available that treat the underlying cause of CF and are dramatically improving lung function as well as quality and quantity of life for people with CF. As a result, more women with $\mathrm{CF}$ are having babies. We gathered a panel of experts in CF care, family planning, high risk obstetrics, nutrition, genetics and women with $\mathrm{CF}$ to review current literature on pregnancies and to provide care recommendations for this unique population.
\end{abstract}

\section{Hosted file}

11-25-20 Pregnancy position paper draft full manuscript - FINAL manuscript guidelines.pdf available at https: //authorea.com/users/379168/articles/495473-pregnancy-in-cystic-fibrosisreview-of-the-literature-and-expert-recommendations

\section{Hosted file}

Figure 1.pdf available at https://authorea.com/users/379168/articles/495473-pregnancy-incystic-fibrosis-review-of-the-literature-and-expert-recommendations

\section{Hosted file}

Figure 2.pdf available at https://authorea.com/users/379168/articles/495473-pregnancy-incystic-fibrosis-review-of-the-literature-and-expert-recommendations 